\title{
Erratum to: Impact of Extent of Antral Resection on Surgical Outcomes of Sleeve Gastrectomy for Morbid Obesity (A Prospective Randomized Study)
}

Emad Abdallah $^{1} \cdot$ Ayman EI Nakeeb ${ }^{1,2} \cdot$ Tamer Youssef $^{1} \cdot$ Hesham Abdallah $^{1} \cdot$

Mohamed Abd Ellatif ${ }^{1} \cdot$ Ahmed Lotfy $^{1} \cdot$ Mohamed Youssef $^{1} \cdot$ Abdelazeem Elganash $^{1}$.

Ahmed Moatamed ${ }^{1} \cdot$ Mosaad Morshed $^{1} \cdot$ Mohammed Farid $^{1}$

Published online: 1 August 2015

(C) Springer Science+Business Media New York 2015

Erratum to: OBES SURG (2014) 24:1587-1594

DOI 10.1007/s11695-014-1242-x

The name of the third author was incorrect in the original article. The correct spelling is Tamer Youssef.

The online version of the original article can be found at http://dx.doi.org/ 10.1007/s11695-014-1242-x.

Ayman El Nakeeb

elnakeebayman@yahoo.com

1 Surgical Department, Mansoura University, Mansoura, Egypt

2 Gastroenterology Surgical Center, Surgical Department, Mansoura

University, Mansoura, Egypt 